\title{
Detecting Thrust Bearing Failure within a Screw Compressor
}

\author{
Carl Pallaver \\ Fermi National Accelerator Laboratory \\ P.O. Box 500, Batavia, Illinois 60510
}

May 1994 


\section{Disclaimer}

This report was prepared as an account of work sponsored by an agency of the United States Government. Neither the United States Government nor any agency thereof, nor any of their employees, makes any warranty, express or implied, or assumes any legal liability or responsibility for the accuracy, completeness, or usefulness of any information, apparatus, product, or process disclosed, or represents that its use would not infringe privately owned rights. Reference herein to any specific commercial product, process, or service by trade name, trademark, manufacturer, or otherwise, does not necessarily constitute or imply its endorsement, recommendation, or favoring by the United States Government or any agency thereof. The views and opinions of authors expressed herein do not necessarily state or reflect those of the United States Government or any agency thereof. 


\section{DETECTING THRUST BEARING FAILURE WITHIN A SCREW COMPRESSOR}

A $3 \frac{1}{2}$ mile ring of over 1000 superconducting magnets are needed to focus and drive the world's highest energy particle smasher. 24 refrigerators supply liquid helium to the magnets; 34 high pressure oil flooded screw compressors supply 285 psig helium gas to the refrigerators.

The 400 h.p. screws are reliable machines that use 45 gallons of oil per minute to seal and lubricate the rotors, lubricate the bearings, and remove the heat of compression. These machines are spaced out in seven buildings over four miles. A minimum of 28 machines must be operating at all times. A contingent of operators start, stop, and monitor any machine from a distant control room.

The 34 compressors have an average of 32,000 hours; 9 machines have over 40,000 hours; the highest is 55,000 hours.

The rotors turn at 3,450 revolutions per minute and are positioned with preloaded precision thrust ball bearings. They are free turning with wo axial movement. The thrust bearings determine the life of the machine. Our experience shows that the machine is in a self destruct mode when a bearing wears more than 2 thousands of an inch. The normal high supply of oil masks the vibrations, noise, and cutting action of the rotors striking the walls when the bearings fail. Higher horsepower is the final message from an unattended, unmonitored machine. We use three methods to detect deteriorating bearings:

1. A simple shaft probe set at .006 inches shuts down the machine when the shaft moves axially. This works well but only protects the main drive rotor.

2. Thermocouples touching each thrust bearing outer race. Four machines are currently in a test program anticipating higher temperature during bearing bailure.

3. Vibration readings taken with an economical hand held meter which measures velocity in inches per second peak to peak. These readings are recorded once a month.

The objective with any moving piece of equipment is to maximize the operating hours without damaging the device. The compressor manufacturer recommends overhauls at 20,000 hours. Our operating statistics indicate 
50,000 hours is a safe limit for the bearings. With a limited, shrinking budget, a sure, economical method is needed to protect our compressors. Recent vibration analysis results have helped determine our needs. Over a five year period vibration readings averaged .05 inches per second peak to peak. Recently, during our monthly readings, vibrations of $.28, .28, .18$, and .29 were measured on a machine that had 43,000 hours of operation. This was the first time in over 8,000 readings that we observed a significant change. Approximately 20 hours later our shaft probe shut down the machine. The machine was restarted and vibration readings at the same locations oscillated from .28 to $.75 ; 4$ hours later the shaft probe shut the machine off again. We replaced the compressor with our spare. upon disassembly we found .009 inches end play on the drive rotor shaft and burnished balls on the thrust bearings.

With this data, it is my intention to place two axially opposed accelerometers on each machine. They are to be inexpensive velocity type, activating a compressor shutdown circuit set at $.35 \pm 5 \%$ velocity inches per second peak to peak. These two accelerometers, within a limited budget, should provide the type of early detection we need. 


\section{VIBRATION ANALYSIS}

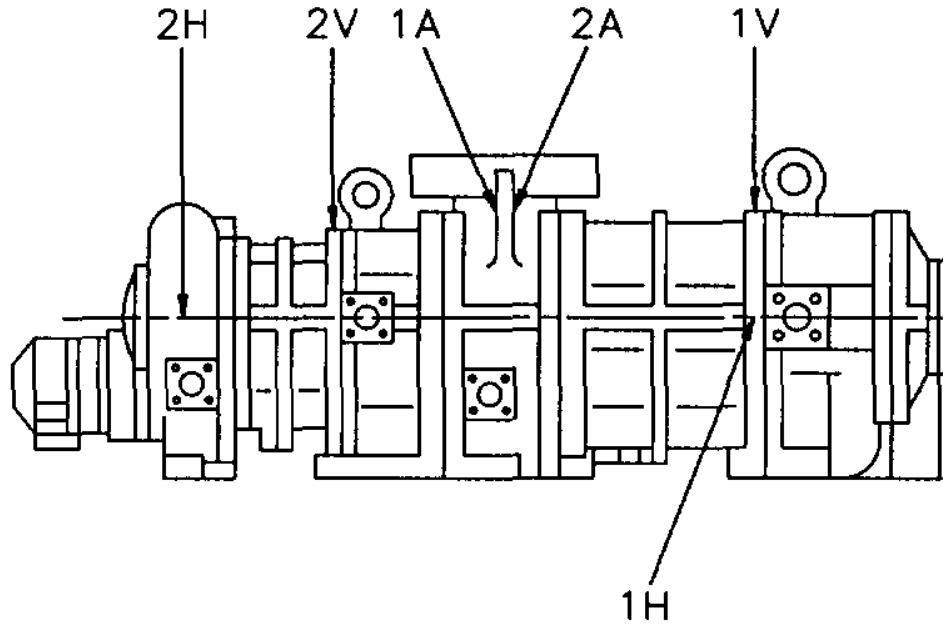

Compressor

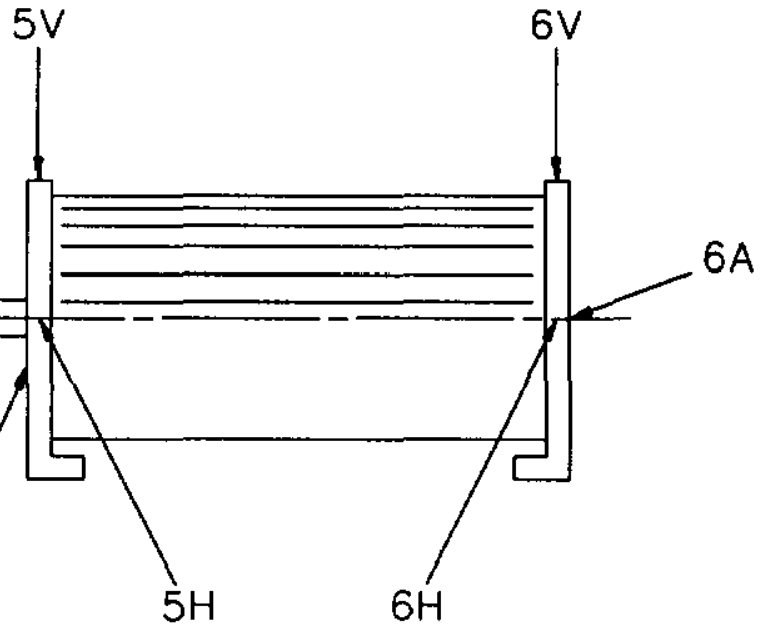

Motor

Location: $\mathrm{D} \varnothing \# 3$

\begin{tabular}{|c|c|c|c|c|c|c|c|c|c|c|c|c|c|}
\hline DATE & $1 A$ & $2 A$ & $1 H$ & $1 \mathrm{~V}$ & $2 H$ & $2 V$ & $5 A$ & $5 H$ & $5 V$ & $6 A$ & $6 H$ & $6 V$ & $\begin{array}{c}\text { Inter- } \\
\text { stage } \\
\text { Press. }\end{array}$ \\
\hline $10-5-92$ & .05 & .05 & .05 & .04 & .06 & .04 & .13 & .09 & .21 & .08 & .06 & .11 & 40 \\
\hline $11-10-92$ & .05 & .04 & .06 & .06 & .08 & .05 & .16 & .10 & .19 & .10 & .09 & .15 & 40 \\
\hline $12-1-92$ & .04 & .04 & .04 & .07 & .08 & .03 & .16 & .08 & .17 & .08 & .07 & .13 & 38 \\
\hline $1-7-93$ & .07 & .07 & .05 & .04 & .07 & .04 & .12 & .12 & .20 & .07 & .08 & .15 & 32 \\
\hline $2-5-93$ & .06 & .06 & .06 & .06 & .09 & .05 & .13 & .12 & .21 & .13 & .10 & .12 & \\
\hline $3-3-93$ & .08 & .08 & .06 & .06 & .09 & .06 & .13 & .13 & .23 & .10 & .13 & .20 & 32 \\
\hline $4-27-93$ & .02 & .04 & .05 & .03 & .07 & .04 & .14 & .08 & .15 & .10 & .06 & .13 & \\
\hline $12-8-93$ & .08 & .05 & .05 & .07 & .05 & .04 & .09 & .08 & .18 & .09 & .10 & .21 & 30 \\
\hline $1-5-94$ & .08 & .06 & .04 & .04 & .06 & .07 & .12 & .08 & .24 & .09 & .08 & .20 & 28 \\
\hline \multirow[t]{2}{*}{$2-3-94$} & 28 & 28 & .09 & .03 & 18 & .01 & 29 & .10 & .18 & .14 & .10 & .29 & 40 \\
\hline & & \multicolumn{9}{|c|}{ REPLACED COMPRESSOR (43KHOURS) } & & & \\
\hline $2-18-94$ & .08 & .08 & .03 & .03 & .07 & .03 & .10 & .07 & .15 & .08 & .06 & .18 & 30 \\
\hline & & & & & & & & & & & & & \\
\hline & & & & & & & & & & & & & \\
\hline
\end{tabular}



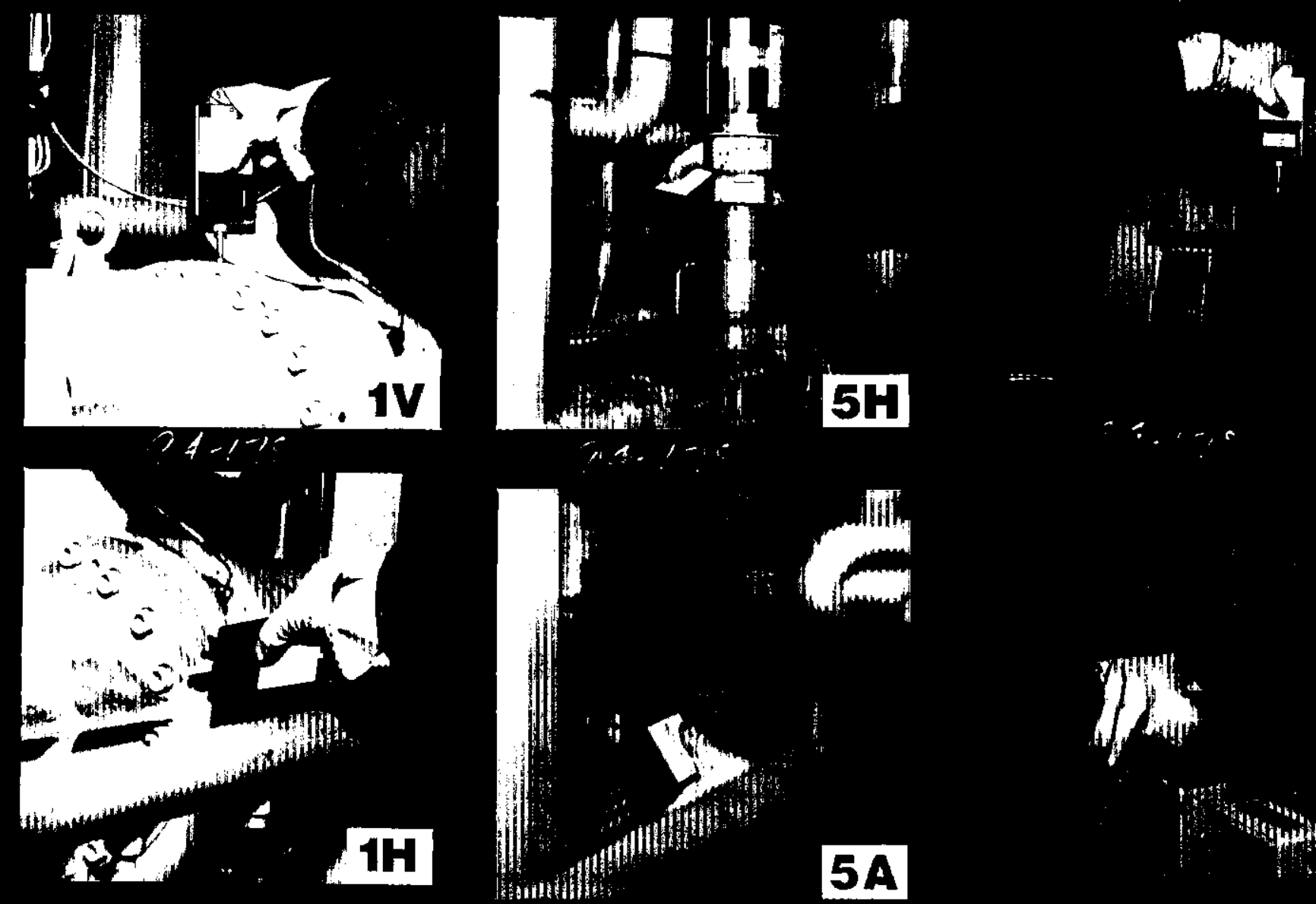

6V
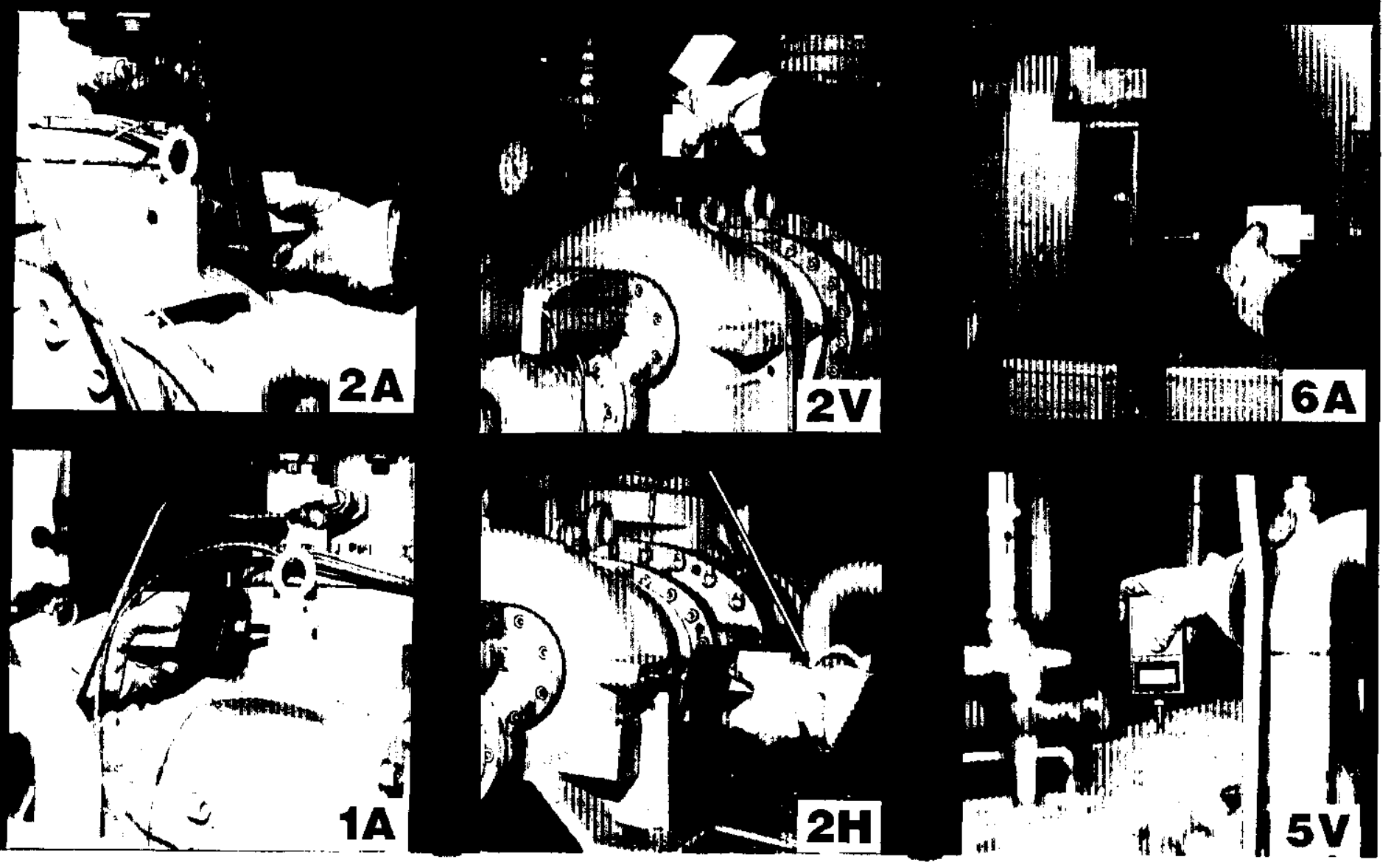

FIGURE 1: VIBRATION MEASUREMENT POINTS ON COMPRESSOR AND MOTOR 


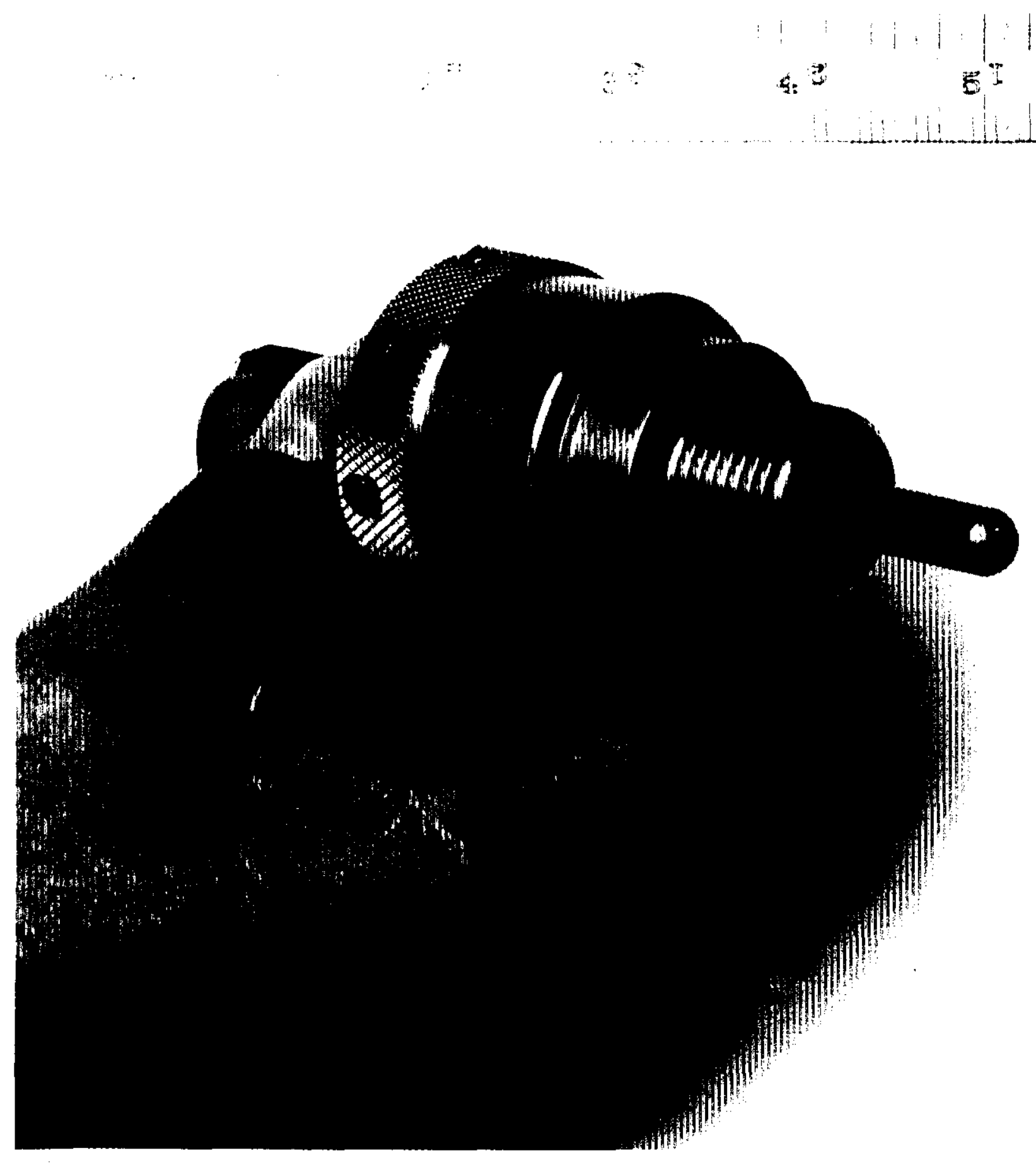

FIGURE 2: SHAFT END PROBE SHUTDOWN DEVICE 


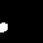

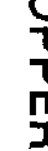

$\sum$

D

ב

ఏ

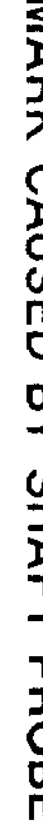

.
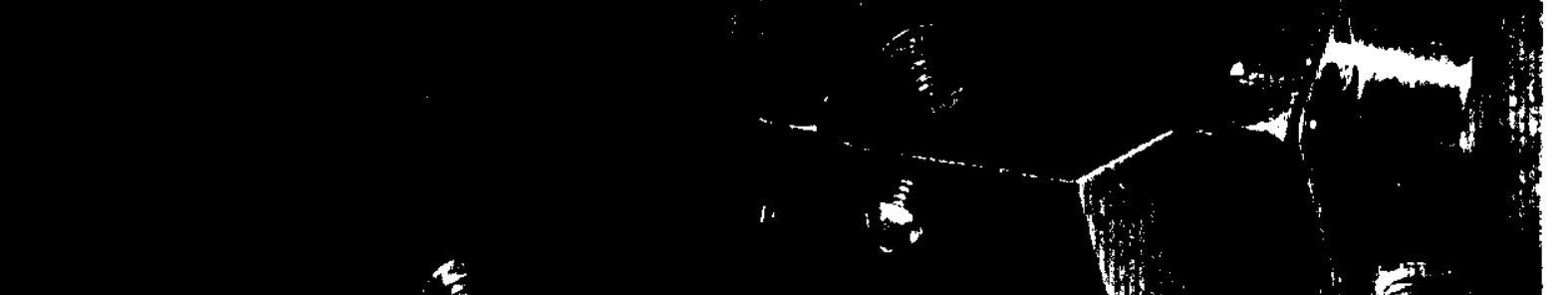


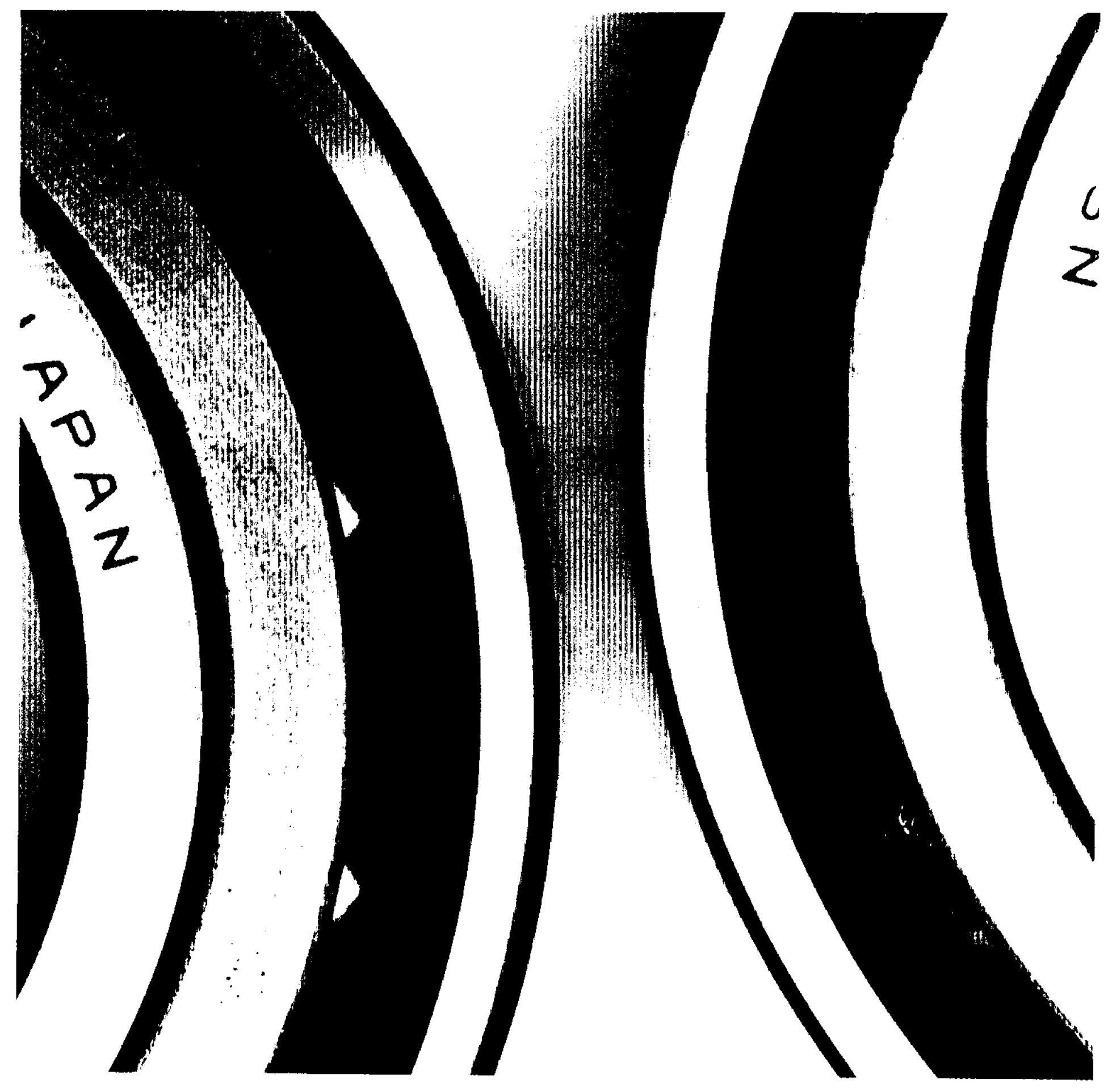

FIGURE 4: WORN, BURNISHED, BALL BEARINGS 


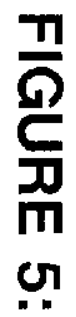

耐 南

刃

号

盆

品

으을

而

驾

음

$\Omega$

음

t?

m

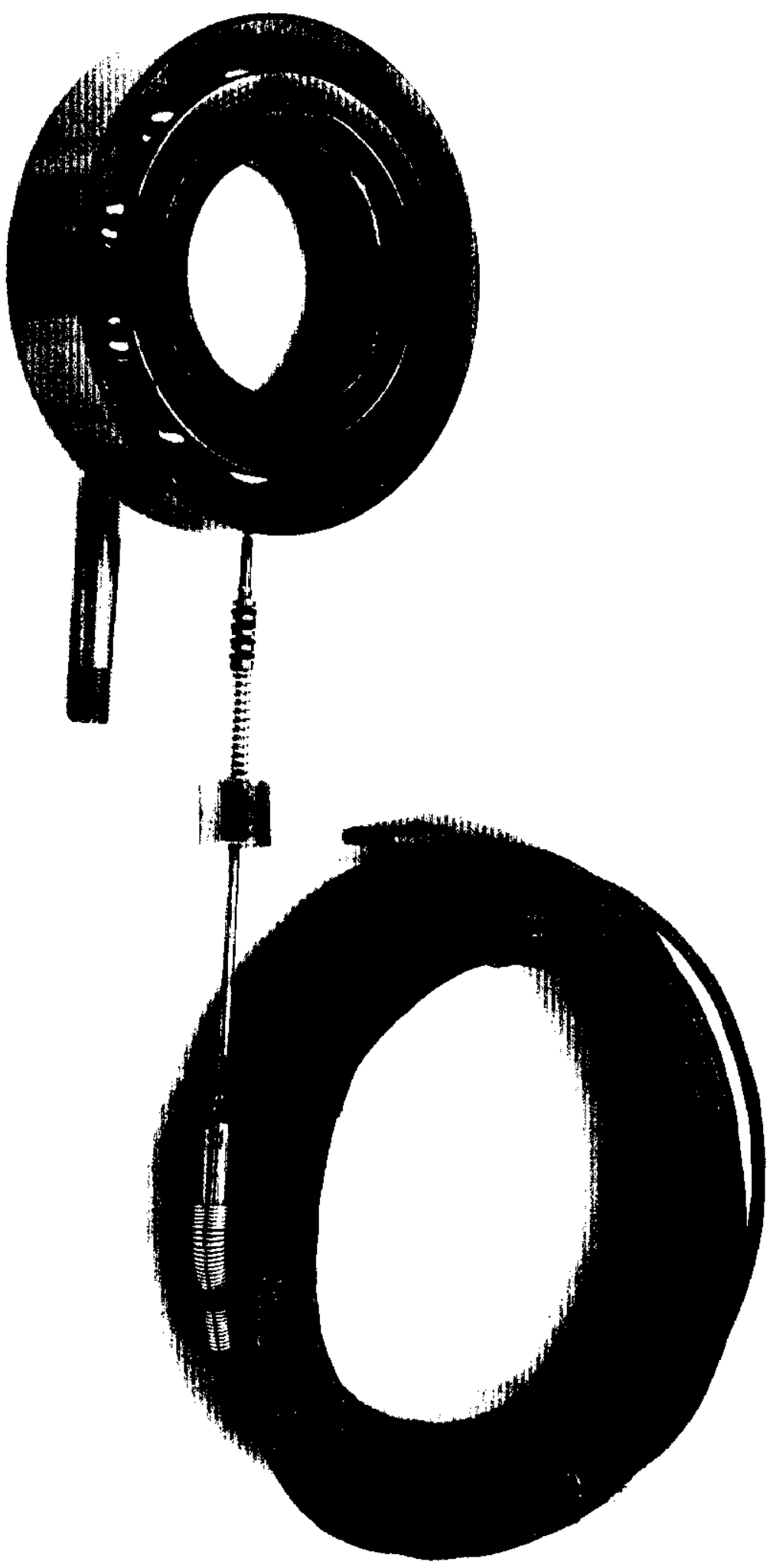




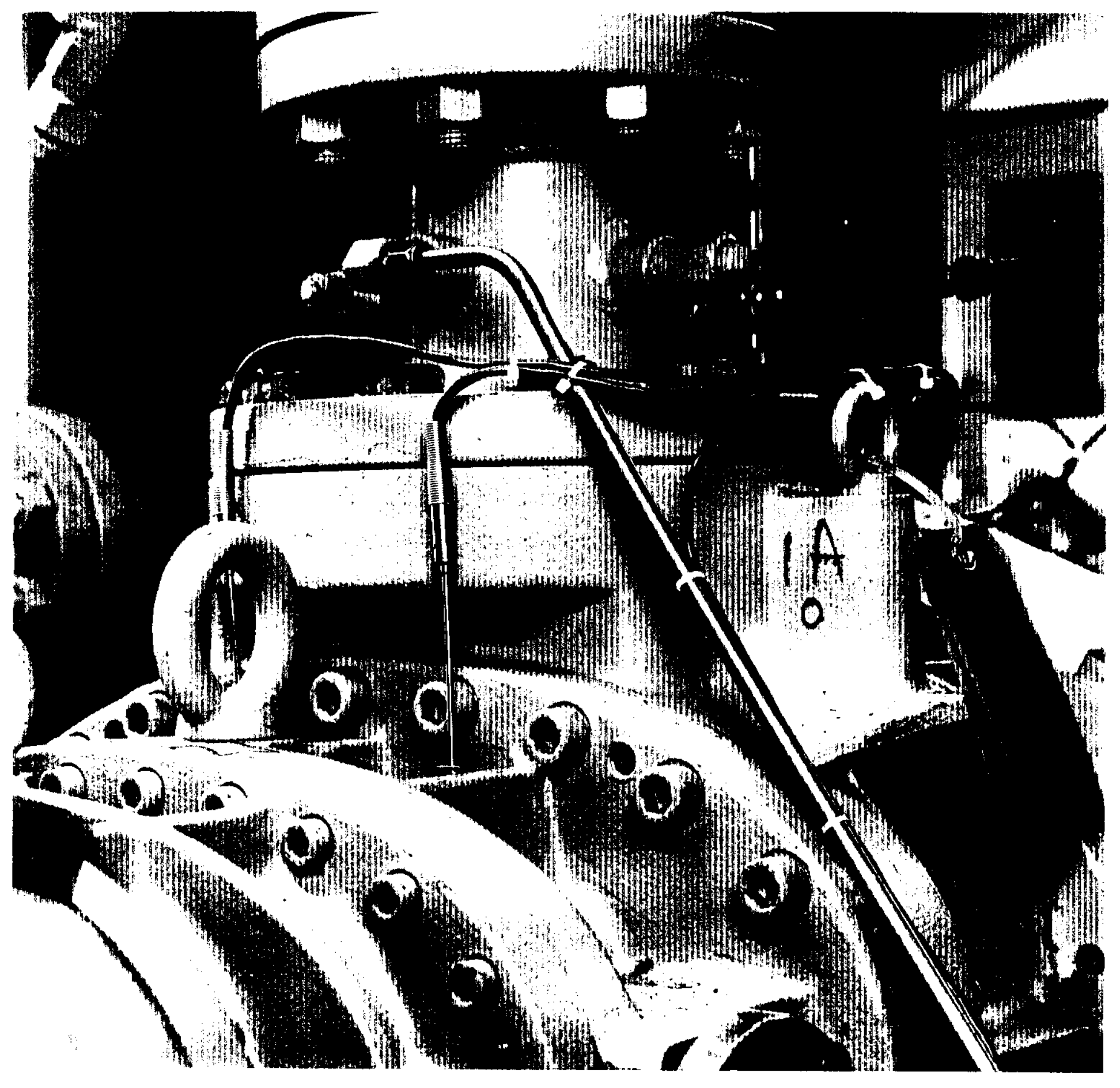

FIGURE 6: POSITION OF THERMOCOUPLE ON HIGH STAGE 


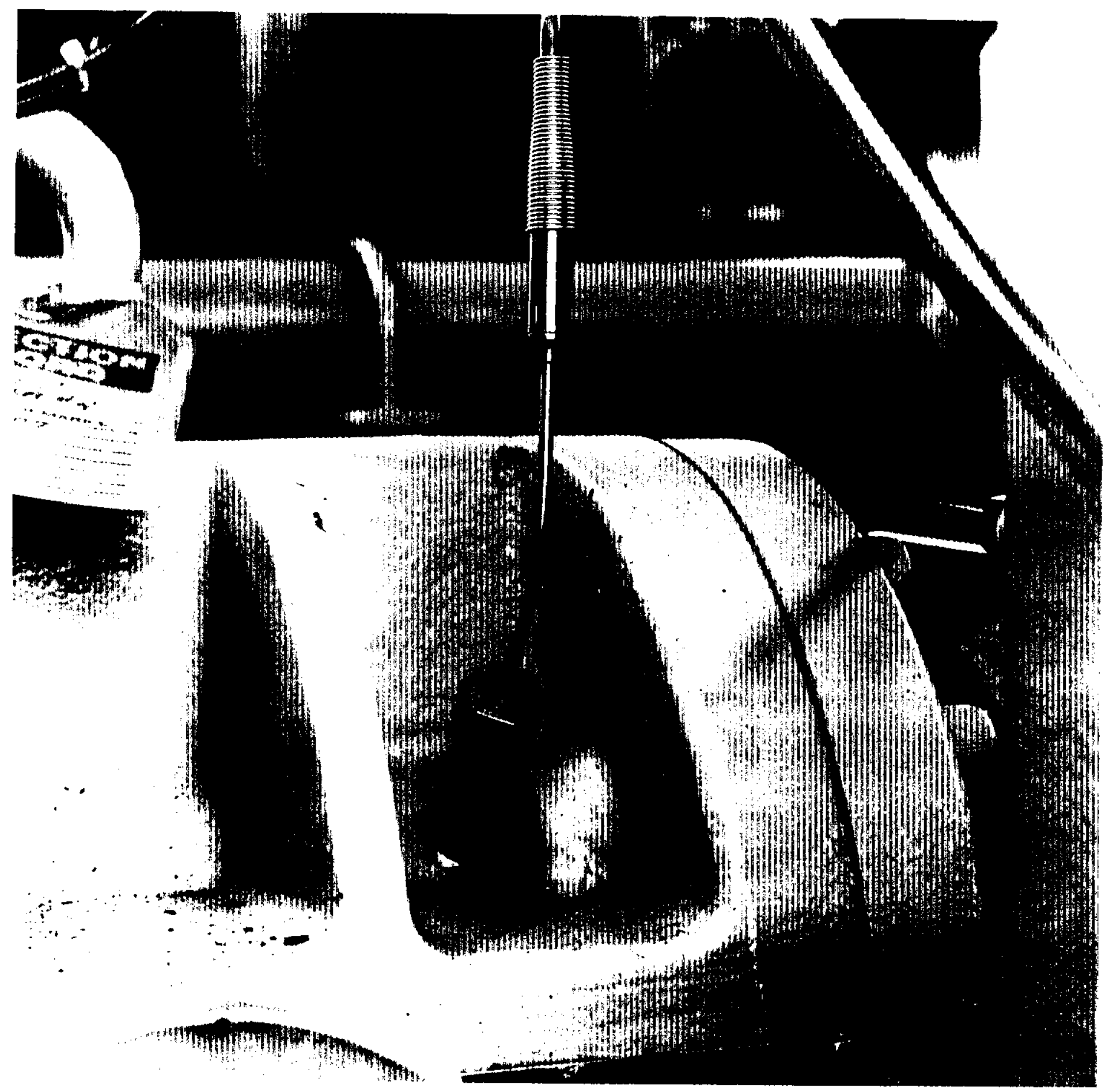

FIGURE 7: CLOSE-UP OF THERMOCOUPLE ASSEMBLY 


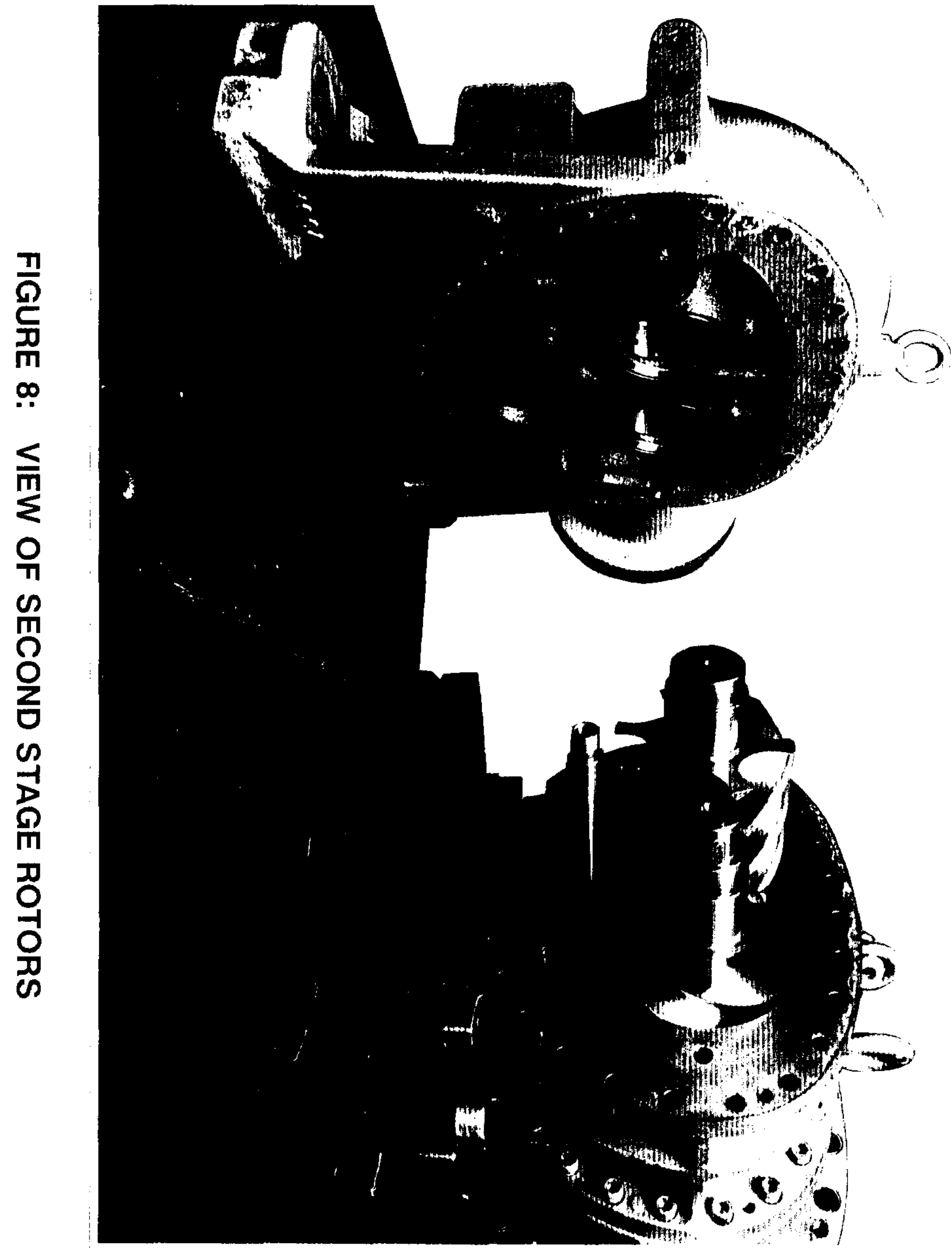

